\title{
Precarity and dehumanisation in higher education
}

\author{
Olivia Mason and Nick Megoran
}

\begin{abstract}
The increased reliance of universities on a pool of highly skilled but poorly paid casualised academic labour for teaching and research has emerged as a defining feature of higher education provision under neoliberal New Public Management. Based on seventeen visual timeline interviews with academics in the North East of England, this article augments and extends existing studies of precarity through a framing of dehumanisation and humanisation. Specifically, we suggest that casualisation is dehumanising in four ways: it renders individuals invisible; it leaves them vulnerable to exploitation; it denies them academic freedom; and it hampers them in constructing a life narrative projecting into the future. We conclude that casualisation is not simply the product of a reprehensible political economy, but that it is an afront to the very meaning and dignity of being human.
\end{abstract}

\section{KEYWORDS}

casualisation, dehumanisation, humanisation, precarity, theological anthropology, visual timeline analysis

In his novel Incredible Bodies, Ian McGuire tells the story of Morris Gutman, who holds a ten-month post in the Department of English and Cultural Studies at the University of Coketown. Gutman had been hired at the lowest legal salary to replace two professors, of whom 'one was drying out and the other touring China on a fat British Academy grant' (2006: 5). Although the advert for this job had proclaimed that Coketown was seeking someone with interests in Queer Theory, diasporic literature and other trendy fields, Gutman - who had held similar jobs teaching twenty-eight different courses at four separate institutions over five years - had learnt that to get such jobs he needed really to do only two things. The first was to 'maintain a façade of scholarly endeavour whilst strongly hinting at one's willingness 
to cheerfully accept untold amounts of work', and the other was 'placating the consciences of the interviewing panel, who always liked to believe that by offloading their own work they were assisting a young person on the path of scholarship and wisdom' (2006: 5). The novel unfolds as Gutman prepares for an interview for a permanent lectureship, a job he knows that he desperately needs to save his career, his health, and his marriage. After twenty-two interviews over five years, the narrator notes: 'He was so tired of this: this job search, this whole process emptying him out like a vast, brutal enema again and again' (2006: 101).

Gutman's fictional plight points to the truth that UK universities are becoming increasingly dependent upon a pool of workers employed to teach and conduct research on precarious and unfavourable contracts. This enables established academics to concentrate on activities aimed at hitting targets and advancing strategic objectives prioritised by managers. A recent report on the issue based on a survey conducted by the University and College Union (UCU 2019) estimates that this 'reserve army' of precarious academic labour is doing between 25 and 30 per cent of the teaching in many universities. UCU argues that this has significant negative consequences including exploitation and financial insecurity, overwork and stress, the exacerbation of racial and gender inequalities in the workplace, and ultimately damaging the quality of education itself.

The extent and harm of casualisation has become well-established in recent writing. In this article, we seek to bring a new angle by interrogating casualisation through the lens of humanisation and dehumanisation, bringing an interdisciplinary perspective framed in particular by the African American tradition of theological anthropology (that is, theological reflection on the meaning of being human) and especially the work of Martin Luther King, Jr. Following an overview of the literatures on precarious work both generally and in academia, we outline research conducted with academics in UK universities using visual timeline interviews. In our substantive findings, we explore how casualisation is dehumanising in four ways: it renders staff invisible to colleagues and institutions; it leaves staff vulnerable to a whole range of exploitative and demeaning practices, placing them in degrading patronage networks; it denies agency and curtails the academic freedom that is a hallmark of our profession; and it prevents them from articulating a long-term narrative of their careers that can provide meaning to their lives. The article concludes with a call to resist casualisation by foregrounding the human. 


\section{Precarity and casualisation in higher education}

In 2010, the CEO of crowd-working company CrowdFlower, Lukas Biewald, told an audience that:

before the Internet, it would be really difficult to find someone, sit them down for ten minutes and get them to work for you, and then fire them after those ten minutes. But with technology, you can actually find them, pay them the tiny amount of money, and then get rid of them when you don't need them anymore. (cited in Marvit 2014)

This is a striking image of precarious or casualised labour - work that is piecemeal; insecure; temporary; and without sick leave, holiday pay, maternity pay, pensions, personal development or long-term security. It is the antithesis of work characterised by hard-won labour rights in unionised sectors of the economies of modern advanced capitalist states. However, far from being exceptional, Trebor Scholz argues that such 'digital labor appears to be the shiny, sharp tip of a gargantuan spear of neoliberalism made up of deregulation, economic inequality, union busting, and a shift from employment to low-wage temporary contracts' (2017: 2-3).

Precarity has become an increasingly dominant frame in critical studies of labour and employment relations more broadly (Strauss 2017). Key interventions from Marxist perspectives (which have long been interested in the dehumanisation of the workforce) seek to define people working in such ways as a distinct class, the precariat (Cant 2019; Standing 2016). But non-Marxist scholars of work also recognise the importance of this development. In updating the conclusion to the 2013 edition of their textbook The Realities of Work, Mike Noon and colleagues reflect on the continuities and discontinuities since the first edition in 1997. Viewing employment in the round, they write that 'one of the important realities of work that has changed significantly is the growing fragmentation and uncertainty of much work experience, with an increasing proportion of jobs subject to greater job insecurity, fewer permanent contracts and more variable work arrangements' (2013: 368).

Although the most egregious examples of precarity can be found in employment spaces such as CrowdFlower, they are increasingly present in the public, education and even non-profit sector under the pressure of neoliberal New Public Management (NPM) (Cunningham et al. 2017). This is the ideology that the public sector should as far as possible mimic, enact and be governed by market principles. NPM sought to erode the public sector 
culture of work as stable, secure and with good pensions and entitlements by making the workplace more 'flexible' through practices such as competitive tendering, differential rates of progression and outsourcing (Brown 2004).

UK higher education has likewise become a major site of neoliberal NPM, with Tom Slater writing polemically that this is turning universities 'into corporations that also happen to hand out degrees every summer' (2012: 118; see also The Analogue University 2019). However, although the problem was being identified in academic discussions at the start of this century (e.g. Hyatt 2004), this critique of the neoliberal university has been relatively slow at picking up on the importance of the casualisation of academic labour. For example, in their authoritative overview of the academic geography profession, Ron Johnston and James Sidaway outline what they call 'the academic career structure' in the United Kingdom. This is presented as a linear diagram proceeding from undergraduate and then graduate student to Lecturer, Senior Lecturer, Reader and finally Professor. Between graduate student and Lecturer, they acknowledge that many people spend time either on a postdoctoral fellowship, as a researcher on a wider research project or a limited tenure teaching post. These are given little discussion, and for Johnston and Sidaway these temporary contracts are merely a parenthesis on the path to professorship - indeed, limited tenure teaching posts are a positive good, an 'apprenticeship' while the 'individual's research expertise' is being 'consolidated' (2016: 2).

This article is written within this parenthesis. Far from being a positive stage on the inevitable trajectory towards permanent employment, such 'casualised' work has become a new business model for universities who have become increasingly dependent upon a pool of low-paid, exploitable and expendable workers employed to teach and conduct research on precarious and unfavourable contracts. These contracts, according to a 2019 survey of UK higher education by the UCU, were widespread with around 70 per cent of the 49,000 researchers and 37,000 teaching staff on fixed-term contracts (the majority of the latter being hourly paid), and a further 71,000 teachers employed as 'atypical academics' not counted in the main staff record. This is the story in the United Kingdom, but there is ample evidence that what has been called 'the adjunct crisis' in the United States (Clark 2019) is occurring across the rest of Europe and elsewhere (Hirslund et al. 2018; Gleerup et al. 2018; Stoica et al. 2019).

The harmful effects of such precarity have been explicated by many scholars (see the moving and disturbing accounts in Hirslund et al. 2018). Georgeta 
Stoica and colleagues outline the pressures of working in '[a] system that is ready to get rid of us as soon as the working contract has finished, offering nothing other than "unemployed excellence"' - including stress, isolation, invisibility, constant movement, and mental health issues (2019: 79). Agnes Bosanquet and colleagues discuss the anxiety amongst early career researchers and $\mathrm{PhD}$ students resulting from 'a deferred state of waiting for academic careers that are yet to come' (2020: 736). Carole Leathwood and Barbara Read (2020) combine casualisation with 'short termism' to argue that last minute and short-term academic appointments negatively impact teaching, limit innovation but also impact security and care towards precarious staff. Vik Loveday (2018) has drawn specific attention to the mental health impacts of casualisation and the onus put on the individual to take personal responsibility for this within the neoliberal academy. The rise of part-time and temporary jobs in US academia, Linda Hose and E. J. Ford argue, ruin the profession, undermine academic freedom and produce 'difficult and minimally remunerative working conditions' (2014: 46). Furthermore, casualisation is entangled within inequality in academia. Tami Navarro argues that women of colour are 'disproportionately represented in the ranks of unsecured, contingent labour’ (2017: 507). While Martina Caretta and colleagues (2018) argue that the effects of precarity have implications for who is able to continue within the neoliberal academy as factors such as gender, class, and mother-tongue affect opportunities. We recognise all this important scholarship on precarity, but want to push deeper in our critique, focussing explicitly on an aspect of casualisation that has been implicit in much of this critique - that casualisation is fundamentally dehumanising. By using the lens of dehumanisation, we centre the lived and personal experiences of individuals in order to understand how casualisation within the neoliberal academy impacts the very meaning and nature of what it means to be human.

\section{Human beings - or human resources?}

Although there are multiple factors behind the increasing shift towards casualised labour within higher education, it has been enabled by the contentious notion that workers are primarily to be seen as 'resources'. Indeed, it is usually 'Human Resources' departments that draw up these poisonous contracts. The idea that humans are resources to be managed scientifically has its origins in the work of industrialist pioneer management consultant Frederick Taylor in his 1911 book The Principles of Scientific Management, 
and in the work of mid-century writers like Elton Mayo (1949; see also O'Connor 1999) and Mason Haire (1970), who believed that 'Human Resource Management' (HRM) could help employers roll back hard-won labour rights. HRM therefore went mainstream in the United States and the United Kingdom under 1980s Reagan-Thatcher neoliberalism (Legge 2005), and has subsequently spread worldwide in business, but also into the public sector, charities and education.

HRM encompasses traditional nuts-and-bolts personnel issues such as recruitment, payroll and sick leave, but goes beyond this in seeking to align individual working practices to an institution's 'vision' or 'strategic objectives' set by managers in the belief that this will enhance performance. HRM is thus about management of culture and meaning in an organisation (Storey 2007). Critics claim there is no convincing evidential base showing that HRM improves performance (Wall and Wood 2005) and worry instead that it devalues workers because 'resources' implies they are simply a means to an end (Taskin and Ndayambaje 2018). If people are considered in this way, then it is hardly surprising that abusive and degrading casualised contracts have come to abound and be seen as acceptable. We need other ways to think about workers as human beings with intrinsic value.

The question of humanisation and dehumanisation has received significant attention across a range of fields in recent years, including feminist philosophy (Mikkola 2016) and international politics (Weinert 2015). However arguably the most active field has been psychology (Bain et al. 2014b), where Jacques-Philippe Leyens wrote a decade ago that 'empirical and theoretical research on dehumanization is blossoming at a growing rate' (2009: 807). However, as Paul Bain and colleagues (2014a) acknowledge, this work has been more successful at analysing dehumanisation rather than identifying more positively what humanisation might be. In using this framework, therefore, we aim to both understand how casualisation is dehumanising but also how it can be humanising. To do this, and move beyond simply providing a critique to actually identifying more positively the characteristics of a humanising workplace, our research turns to African American theological anthropology and in particular the work of Martin Luther King, Jr. This is because this tradition articulates a clear foundation for human value and insists that a necessary correlate of thinking through practices that humanise individuals is both critical social reflection and radical socio-political change. Although sometimes narrowly seen in popular White historiographies as a 'civil rights activist' whose brave challenge to a racist minority helped bring 
the American dream to all (Harding 2000), Thomas Jackson (2007) argues that King's thinking and activism used broader, universal concepts that were not merely explored and developed in his specific context but were articulated to encompass a more radical vision of global human rights. The workplace was a key site of thought and struggle for King who, indeed, was murdered in Memphis, where he had travelled to support striking sanitation workers.

King's opposition to what he often identified as the three evils of racism, poverty and war was premised on the African American reading of theological anthropology (Wills 2009). Building on the legacy of nineteenth-century thinkers like Frederick Douglass, the central idea in this tradition was the ethico-political implications of the Biblical concept that human beings are created imago Dei, 'in the image of God'. ${ }^{1}$ Western theological anthropology has been preoccupied with the debate as to whether this referred to capacities, attributes or functions of being human (Cortez 2010), but in contrast we would contend that focus should instead turn to how African American thought reads it as primarily ethical in the context of social and political struggle.

For example, on 6 July 1965, King was invited to address a congress of the predominantly White United Church of Christ in Chicago on the topic 'Man in a revolutionary world'. He argued that segregation was wrong first and foremost because we are made in God's image: 'The innate worth referred to in the phrase the image of God is universally shared in equal portions by all . . . Every man must be respected because God loves him'. This innate worth - the basis of King's positive account of humanisation - is obscured, he argued, when people are seen as mere tools rather than humans, with the primary concern of employers being 'performance not well-being'. In contrast, King insisted:

Man is not a thing. He must be dealt with not as an 'animated tool', but as a person sacred in himself. To do otherwise is to depersonalise the potential person and desecrate what he is. So long as the Negro or the member of any other oppressed group is treated as a means to an end; so long as he is seen as anything less than a person of sacred worth, the image of God is abused in him and consequently and proportionately lost by those who inflict the abuse. (King 1965)

It would, of course, be wholly inappropriate to draw any equivalence between the sufferings of contemporary British academics with those of 1960s African Americans. Rather, the general principles that King articulated 
so brilliantly from his own context provide a new optic for us to view casualisation in our settings. For King, humanisation is about recognising the intrinsic, positive value of beings created imago Dei, something he also rephrased in more secular terms as 'the dignity and worth of human personality' (King 1986 [1967]: 295). His insistence that we ask whether people are treated in ways that recognise and respect their intrinsic dignity is both morally important and empirically productive by furnishing us with a unique set of questions with which to interrogate the effects of casualised labour in the current business models being favoured by UK higher education providers.

\section{Methods}

This article explores how academics experience work as either humanising or dehumanising, with an emphasis on contractual type (fixed-term or openended). We conducted visual timeline interviews with academic staff at a number of higher education institutions in the North East of England. Visual timeline interviews are a method developed to explore career trajectories retrospectively (Mazzetti and Blenkinsopp 2012). Interviewees were asked to tell the story of their working life by drawing a timeline, using visual metaphors as far as possible. They were requested to draw particular attention to how they came to be academics, and to subsequent career high and low points, and then identify moments or periods on the timelines when they felt treated in humanity-affirming or dehumanising ways, and to reflect on these. Finally, drawing on King's insistence that our intrinsic humanity is recognised in the workplace, they were asked how universities could ensure that they are treated in humanity-affirming rather than in dehumanising ways. Each interview lasted between one-and-a-half and four hours. We conducted seventeen visual timeline interviews with academics as part of a comparative project comprising interviews with fifty-five people working in higher education, secondary education and churches. These were selected as fields in which people have a strong sense of vocation, in that they believe they are carrying out meaningful work. This means that people may be more willing to accept poor working conditions because they feel that they are striving for a higher cause (education, human progress, science) rather than simply working for an employer (Bunderson and Thompson 2009).

This research was published in a wider report by Newcastle University and the William Leech Research Fund in July 2019, Human Resources? Recognising the Personhood of Workers in the Charity and Public Sectors. 
It found that academics were highly self-motivated, generally being driven by an enthusiasm for their subject, a desire to advance the common good through discoveries and research, and a commitment to education as a public good. The report identified eight 'habits of highly humane workplaces' - that is, characteristics of workplaces that respondents marked as humanising if present or dehumanising if absent. These were the ability to make a difference; being trusted with freedom and autonomy; insulation from the harmful effects of audit cultures; being listened to; the quality of human relationships; 'the magic power of human sympathy' (employer empathy at high and low points of life); communities of care; and contractual affirmation.

It is the stark differences reported by staff in permanent and casualised employment in higher education under this last heading, 'contractual affirmation', that forms the basis of this article. 'Contractual affirmation' is the validation of self as having worth in the eyes of others experienced at the awarding of jobs, promotions and career rewards. For example, Craig had applied for more than eighty lectureships in different countries over a two-year period working on a casualised contract. He relayed that this led to a growing 'sense of panic and discouragement', asking 'what has the system done to me?' after a decade of preparation by undergraduate, master's and doctoral study. He described this as very dehumanising. In contrast, finally being awarded a permanent lectureship was humanising, - 'being offered the job, being given start-up research money, and being told that I would be eased in gently with the workload'.

Following the offer of a job itself, promotion was marked by many people as humanising. Andrea described her promotion to Senior Lecturer as a 'restoration of balance'. She felt she had been looked down on by some colleagues who thought she could teach but not do research, and so had 'crap' administrative roles dumped on her. Suddenly, she said, those colleagues did not treat her with the same disrespect. Every academic we interviewed on a permanent contract pointed to such moments of contractual affirmation as amongst the most humanity-affirming of their working lives. In contrast, staff on casualised contracts lacked such affirmation and reported finding their working conditions dehumanising.

This research identifies four ways in which academics working on casualised and precarious contracts are treated in dehumanising ways. These will be considered here in turn. Our findings are structured around the narratives of our interviewees as reported in the visual timeline interviews. All names have been anonymised. 


\section{Findings}

Invisibility

The first dehumanising aspect of casualised labour that we identified in our interviews was the invisibility of those subject to it. Temporary staff are amongst the most marginal and invisible in a university, and institutions can all too readily mistreat them by failing to recognise their equal personhood.

As a PhD student, Sunita embarked upon her life as an academic with a sense of exhilaration. Having a strong sense of vocation, she described academia as 'the best job in the world'. However, she continued, 'the bubble burst' as soon as she moved into a position as a temporary research assistant, a role created to help free a senior academic up for managerial duties. She described the life of her and her colleagues as being in 'the sweatshop of academia'. This was not simply about lack of long-term security and choice in research topics; it was that she was suddenly rendered less visible to the mechanisms of departmental administration. Two incidents in particular stood out for her. The first was that she was not allowed to have a name plaque on her office door, because she was not permanent - even though she was working as hard as permanent staff members, at the same intellectual level, and indeed collaborating with them. The second was that the departmental administrators would not book conference travel for her and other Research Associates, telling them it was 'because you are not academics'.

Apparently minor issues, like having one's name on a door or being able to access travel booking facilities, were thus experienced as intensely dehumanising, in effect setting up casualised staff as second-class academic citizens. The very names of roles announced this from the start. Whereas once universities employed 'Temporary Lecturers', now they routinely label roles as 'Teaching Fellows' or 'Teaching Assistants'. Susannah, who had worked on a series of such contracts described them as dehumanising, visibly marking certain academics out as less intellectual and academic than their peers on permanent contracts as lecturers. They are described as Teaching Assistants, she explained, but this may be a total misnomer as often they are not 'assisting' at all but are autonomously doing work of the same type, value and quality as any other lecturer. The naming of roles is important, she insisted, and even having 'Teaching' in the title is dehumanising: 'Teachers belong in schools, lecturers in universities', she said.

But it is not simply that casualised staff can be invisible to impersonal systems of 'HR' or have dehumanising job descriptions; is it that casualised 
staff are often omitted from the rites of passage that are characteristic of being human. People do not spend time getting to know temporary staff, inviting them out for a coffee to ask about their work, asking them home to dinner with their families, or meeting up socially. 'People rarely see you, they don't think about you, and they don't care about you, because you're only ever temporary', as Amelia put it, starkly. This invisibility continued from start to finish. 'No one ever says farewell' - those in the most vulnerable temporary roles, such as the hourly paid, 'are never introduced to anybody so why should you be given a farewell?'

Casualised staff are amongst the most marginal elements of the academic workforce, and the very nature of these employment conditions often creates an invisibility that is dehumanising in a myriad of ways.

\section{Vulnerability}

This invisibility enabled a second dehumanising aspect of casualised academic labour, vulnerability. Casualised staff are routinely subject to pressures to accept unfair and exploitative work practices, but because of their vulnerable position, and because these demands often come from the very managers whose patronage they need for the promise of future work, they are not in a position to refuse.

For example, the majority of interviewees on casualised contracts reported having to work much more than they were paid for - often because inadequate time is allocated for teaching preparation. A common form of this is giving people contracts of only nine or ten months of the academic year and expecting teaching preparation time to occur outside these. The expectation of performing unpaid preparation time was not just placed on staff at the start of the academic year, but for many people continued throughout it. For example, Kyle spoke from his extensive experience of casualised labour at a number of so-called 'Russell Group' universities. These jobs varied in their nature, from hourly paid teaching at one place to a 0.5 FTE contract over ten months at another with no real continuing professional development. The rationale given for not employing him on a full-time contract in this latter position was that the teaching material already exists, so zero preparation time is needed. But, for example, he recounted that he was given lecture slide shows with thirty photographs on them and no notes: it would have been absolutely impossible to simply turn up, with no preparation, and deliver a coherent lecture that he would have felt professionally satisfied with. 
The vulnerability of casualised staff further left them open to a whole range of exploitative practices that, whilst they may not have technically been illegal, were certainly experienced by academics as dehumanising. Amelia described one university she worked for on a temporary contract as regarding her as 'a cash cow'. Although employed to do the teaching of someone bought out on a grant, managers wanted her to work on other people's grant bids, take local field trips and the like.

Similarly, Bruno recounted a gradual change in the attitude of people working around him as he remained longer and longer on temporary research contracts. As a child, he said, he had developed a fascination with his subject which he was able to carry to university and eventually a $\mathrm{PhD}$. He experienced strong affirmation by getting a single-authored article published relatively early in his career, as a result of which 'I felt like I belonged to academia', he recounted - external recognition which made him feel, 'Oh my gosh, I'm worth it'. The PhD viva was 'another "I'm worth it" moment'. Similarly, winning post-docs after the $\mathrm{PhD}$ made him feel like a high-flier, as he developed and honed certain technical skills that were much in demand in his discipline. However, he described a slow change over time as he moved not to a permanent post, but between post-docs and other temporary research positions. As he put it:

Progressively in my school, people have realised I had a certain expertise and they are using this expertise and taking advantage of me. Instead of helping me become an independent academic, they say: 'We should take advantage of him as much as we can'. This is not intentional, but people say: 'You already work here, you do not have your own PhD students, so you can help me out; I've already talked to your line manager'. If they ask my line manager first, what can I say? This is not a plot, this is the attitude I would have it myself if I was under pressure and someone had technical skills: I wouldn't think how this would help him get a permanent job, etc. Academics are so pressured that they take advantage of post-docs who have a particular expertise.

This exploitation was a product of his vulnerability, a vulnerability that meant he could not easily challenge it. Bruno found this dehumanising, but recognised it was not about particular unethical individuals, but a structural result of a system increasingly reliant on casualised labour.

Another academic, Keira, spoke of her relief at getting a permanent contract after years of casualised work because it represented 'freedom to step 
away from compromised standards and people who break the rules'. She gave the example of a supervisor insisting she add not only the supervisor himself as an author on one of her publications, but also his partner who had only a perfunctory involvement in the article (reading it once and giving brief comments, but no active involvement in the research). This was an unfair request, but one she felt powerless to resist as the continuation of temporary work and the promise of permanent work in the future seemingly depended upon this person. Vulnerability is also dehumanising because it is not equally spread, and is shot through with power relations. For instance, the precarious nature of academia results in many international employees not being able to stay in UK academia, as temporary contracts do not meet their visa restrictions. Furthermore, last minute extensions and less than full-time contracts have impacts on mental health, and those with caring commitments, particularly women, are less able to survive under such precarity (see Caretta et al. 2018).

Casualised staff are routinely subject to pressure to accept what could be seen as unfair and exploitative work practices, but because of their vulnerable position, and because these demands often come from the very managers whose patronage they need for the promise of future work, they are not in a position to refuse. The present culture of casualised academic labour inculcates a culture of dehumanising vulnerability. This vulnerability is rarely made visible or discussed. Staff are under great pressure to accept a whole range of exploitative practices, and often find themselves isolated and without the ability to seek help.

\section{Lack of Agency}

Akin to the vulnerability of casualised staff, in their accounts of dehumanisation, was, thirdly, their lack of agency.

Academic university work in liberal democracies is set apart from most other spheres, in that its governing principle is 'academic freedom'. This does not simply mean the right to voice an unpopular opinion if it follows from one's research and reasoning. It also means the right to choose what topics to research, irrespective of pressure from managers and governments, pressure which will often be experienced in terms of pressure to follow funding streams. According to the authoritative 1997 UNESCO Recommendation concerning the Status of Higher-Education Teaching Personnel, this 'academic freedom and institutional autonomy' also applies to teaching. Teaching staff 'should be given the essential role in the choice and adaptation of teaching 
material'. Further, 'higher-education teaching personnel have a right to carry out research work without any interference, or any suppression, in accordance with their professional responsibility and subject'. In interviews with academic staff on permanent contracts, it formed the lynchpin of what made for the most humanising workplaces: when they were given the ability to choose research topics and teaching subjects, when trusted to organise their own time, and when able to choose the networks and communities in which they located themselves. In stark contrast, workplace accounts provided by casualised staff revealed that they frequently experienced the curtailment of freedom, the denial of agency, and the absence of trust as dehumanising. This can be seen in the examples of Oscar, Amelia and Keira.

Oscar's experience as an academic reflects this curtailment of freedom. Indeed, freedom was the key theme in his career narrative. As a young man, before going to university, his first job was inputting data in a county council office. Although he had no contact with members of the public, and although his office was a windowless basement, he was forced to adhere to a strict dress code and had no freedom whatsoever in the task. He loathed this sense of being controlled, and so pursued an academic career, including a $\mathrm{PhD}$ that took him to many interesting places. Following the PhD, however, he moved between a series of temporary jobs in a period he describes as his 'precarious years'. These 'anxious years' were negative and unstable. At one point, he had jobs in three different universities in three different cities, spending hours each week travelling between them, as well as doing some public sector work using his academic skills. He found this whole period dehumanising because of a lack of freedom: freedom to commit to a certain place, freedom to choose what to do, and freedom to mould and shape the work he was doing on somebody else's bequest: 'I was a tool at somebody's disposal', he reflected.

\section{Freedom to set teaching and research goals}

Amelia was asked to teach on a module that she regarded as being of dubious quality. The entire module was being taught by 'Teaching Fellows' with no background in the relevant scholarship: 'It was a fraud' to the students, she concluded, and told her managers that it would lack integrity if she ran it, so said she could not. However, she was forced to lead the module: 'I wasn't allowed to refuse things', she recounted, meaning that the sense of value, worth and satisfaction she got from teaching was lost. 'I felt completely powerless', she summarised - a feeling she marked as extremely dehumanising. 
We saw above that Keira experienced years of working on temporary contracts before getting a permanent job, and that the vulnerability of that former position was dehumanising. But it was also dehumanising because it denied her the essential academic freedom and agency that academics rate so highly. Her essential point was that her manager was the grant-holder whose money enabled her to remain at the university, but he directed all her energies towards his own research goals, without consideration of her career hopes. Following her $\mathrm{PhD}$, she did a series of temporary jobs, including demonstrating and lecturing, before spending many years working on temporary contracts for this one manager. Under him, she complained, 'my teaching wasn't valued, and my individual research goals weren't valued. My supervisor was following grants in big fields, and I had no freedom to pursue my own topic'. The structure of hierarchy in research that empowers permanent staff with grants to employ casualised staff to help with their research is conducive to the university doing well, she reflected, 'but not conducive to me being a person'.

Happily, Keira eventually got job as a Lecturer, and she viewed this primarily through the lens of freedom. It 'gave me a sense of purpose', she said - 'freedom to research for its own sake, and the pleasure of it . . . freedom to step away from compromised standards and people who break the rules', giving her a 'renewed sense of self-worth'. Her annual reviews, with a different person, are now positive and supportive, because they operate on the basis of a 'flat hierarchy', conversing with a colleague in the same enterprise, rather than 'talking to the person who controls my funding'.

Such accounts of freedom and a lack thereof go against principles at the heart of modern universities. The Magna Charta Universitatum defines the university as 'an autonomous institution at the heart of societ[y]', and freedom, autonomy and trust are its distinguishing principles. ${ }^{2}$ The more that academics are enabled to exercise this freedom in their teaching and research, the more they experience the workplace as humanity-affirming. In contrast, the culture of casualised contracts is severely curtailing this freedom for many academics, who thereby experience work as increasingly dehumanising.

\section{Inability to project into the future}

In his 1998 book on the effects of new capitalist labour on the workforce, The Corrosion of Character, Richard Sennett argues that new forms of 'flexible' 
work are deeply damaging as they prevent people rendering a long-term narrative of their lives that can provide meaning. Our interviews showed that casualised work was dehumanising in precisely this way, in that it denied academics the ability to think about their work and life over the long term.

Madeleine described her extended period of working on a succession of casualised contracts as dehumanising, because rather than being able to think of her career in terms of years and decades, she was instead going from semester to semester hoping to stay in work. She emphasised that, as time went by, rather than enjoying the excitement of building a career, it becomes more and more depleting as 'you start to look unemployable if you have been an RA for six or seven years'. She explained that the holy grail of a full-time job drove them on:

During this time, we were told that if we worked hard enough, got enough publications, got grants, then we might one day get a full-time academic job. But as someone in this position said to me: 'That's a "just so" story'. At the same time, I had three young kids, and my husband was often away or working late - I couldn't do all the networking in the evenings, and more nursery places would have helped. I had three babies, no grants, few papers and was exhausted.

Although these were described as 'temporary contracts', Susannah said, 'they became my permanent career, there was nothing temporary about it'.

Whereas Keira experienced her series of temporary contracts as keeping her in a static position, rather than being able to move forwards, for Amelia the vagaries of the casualised contract market were experienced variously as backwards movement as well as being forwards or static. When offered her first position, a nine-month 'Teaching Fellow' post, she described it as her 'dream job' to start with, with 'an office all to myself, with my name on the door', authority over a new module, mentoring, and being able to go 'drinking with colleagues' in a supportive culture: 'My sense of prestige went up'. However, the following year she was offered a position in the same department as a 'Teaching Assistant' - lower status, but at least with the relief of being delivered from unemployment, even though she had to go through the demeaning process of 'begging for extra teaching'. The following year, she was again offered a 'Teaching Fellowship', but not even short-listed for a full-time job in the department: this made her feel that 'I was a useful pair of hands, right at the bottom'. With lengths, types and even names of 
position changing from year to year dependent upon the vagaries of funding sources and HR policy, the possibility of being able to plot a life-course was a hopeless yet still painfully tantalising fantasy.

This structural impediment to getting out of the cycle of dehumanising, temporary work was described eloquently by Bruno in a pyramid he drew as part of his interview (Figure 1). He pictured it as consisting of temporary staff on the bottom and permanent staff on the top:

I've read somewhere that the academic pyramid is similar to the drug dealing pyramid. At the bottom there are drug sellers on the street, at the top, the big narcos. The sellers take the risks - they may get shot, go to prison, get arrested, but they take the risk to climb the ladder. Those at the top have risks too, but they need the others at the bottom to do their work. It is a cycle. If I get to the top of the academic pyramid, I will take advantage of post-docs too, there is no way out: I will help them, of course, give advice, assist in developing skills to establish their career, but it is structural.

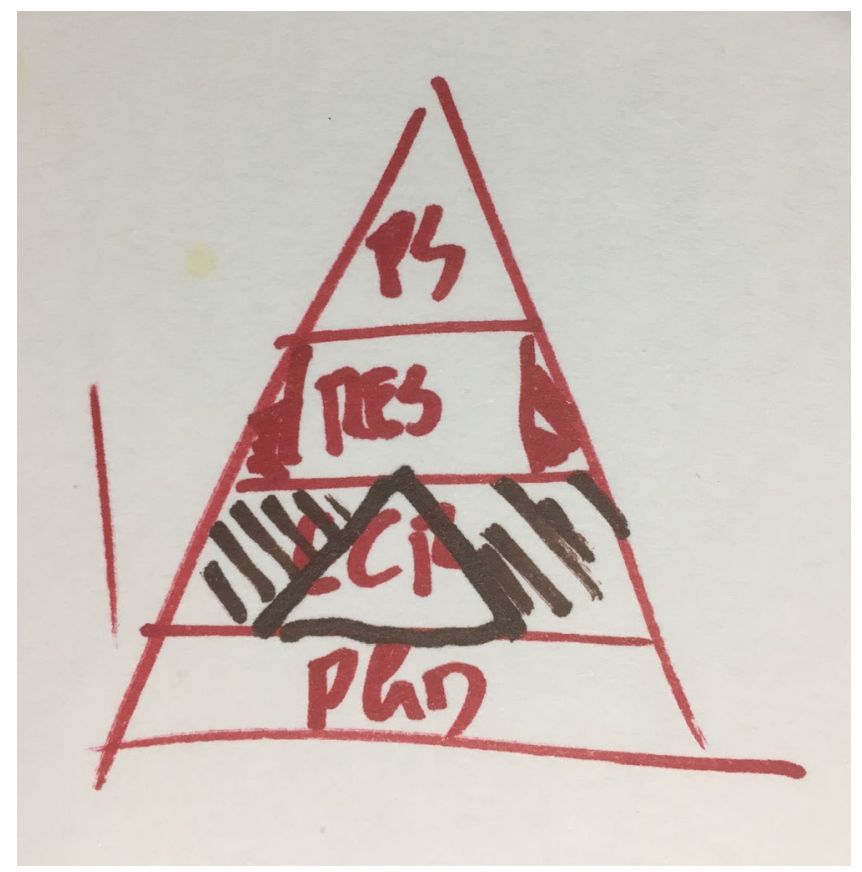

Figure 1. The academic pyramid 


\section{Denial of narrative}

A large-scale survey by the UCU in 2019 reported that 97 per cent of respondents on a fixed-term contract said that they would rather be on a permanent one. Temporary contracts prevent people from making long-term plans about family life, and these have specific equality and diversity impacts: for example, women are often not entitled to maternity leave because they have worked a series of temporary contracts rather than a single permanent one (see Caretta et al. 2018). The hypermobility required of some people working fractional and temporary contracts can also mitigate against the forming or maintenance of stable relationships in the same place that many people desire as a prerequisite to start a family. Our research shows that this is not just about job and income security and the ability to plan for families and mortgages, however. It is also a fundamental question of treating people in humanity-affirming ways. The capacity to envisage a future and tell a longterm narrative of work, career, research plans and vocation provides meaning and order to our lives. Casualised academic labour is thus dehumanising in this regard.

For example, contrast the visual timeline interviews of William and Kyle. William is an emeritus professor who was inspired as a child to pursue a career in science. Beginning his first academic job in the 1960s, he drew an impressive visual timeline. A particularly satisfying aspect of this for him was pioneering new teaching in his institution. Not only did this train large numbers of graduate students, who went on to do work that impacted both academia and industry but it also had a nationwide impact on the discipline, as other UK universities adopted his approach. A further highlight was devising and developing a new drug for cancer treatment that took twenty-eight years from the inception of the idea to formal licensing for public use. Of course, there were difficult periods of that story, too, but on the whole he could reflect that he had always 'enjoyed being an academic'. As he gazed at his completed timeline after an interview of over two hours, he said that this was the first time he had ever told his life story in such a complete way before, and found it moving and satisfying.

In contrast, Kyle has spent years on casualised contracts. At the end of our interview, we asked him: 'What could universities do to treat you in more humanity-affirming ways?' His answer was striking: 
Not have 'Teaching Fellows'. They hardly existed ten years ago. When I was a PhD student, we had these discussions about career pathways. We expected to complete our PhDs, to spend time as research assistants or post-docs, etc., and then get lectureships . . . Teaching fellowships are incompatible with a job market that expects research outputs. What I need to do to get a job [research and publish] is incompatible with the job description [I have now] - that's the bit that doesn't treat me like a human.

The mass-casualisation of the academic workforce is a business model that prevents large numbers of people from being able to gain permanent employment, whilst still holding out that prospect as the ideal. This is dehumanising. As Oscar put it clearly: 'Fixed-term contracts don’t value a future - no one is investing in your future. There is not a commitment to your future from those people who are relying on you to build their future'.

\section{Conclusion and implications}

At the centre of Martin Luther King's life, world view and political activism was what he called the dignity of 'somebodyness' (Baker-Fletcher 1993) that every human being must be treated not as an 'animated tool' but as a person sacred in themselves (King 1965). King warned of the dangers that occur when we 'thingify' people - that is, we treat them as a means to an end (King 1986 [1967]). Although King's work was focussed on a specific context very different from ours, his development of what Jackson (2007) describes as a move from civil rights to reflection on universal human rights enables us to view casualisation with a new optic. This optic is one that insists we ask whether people are treated in the workplace in ways which they feel respect and recognise their inherent human dignity. As our research shows, the relatively recent emergence of mass casualised labour in higher education must be seen in multiple ways as dehumanising. Staff are treated not as human beings of equal value to their colleagues, but as second-class academic citizens, as 'resources' to be deployed to further strategic visions and marketing strategies of Vice Chancellors and governing boards. While much important research has highlighted the impacts of casualisation, through our methodological approach and our narrative structure we have focussed on the means through which casualisation dehumanises individuals. To be more specific, we illustrated how casualisation is dehumanising in four ways. 
It renders staff vulnerable to exploitation, making them dependent upon the goodwill of others. They are seen as simply a cog in a machine. This vulnerability itself is uneven with certain individuals being more vulnerable within these structures of precarity. We outlined the particular problems with collaborative projects and the invisible power of principal investigators. It makes them invisible, unseen or overlooked despite often being core teaching or research staff. They are not given names on their office doors, and their personhood is denied. It denies them academic freedom, in particular the freedom to choose what to teach and research. They are programmed to meet the needs of the employer not their own. Finally, it prevents them from projecting into the future and articulating a coherent narrative about their lives, which is important for making life meaningful for individuals. In short, it treats academics primarily as things not people.

Elsewhere, we have set out a series of suggestions for governments, universities, trade unions, research funders and charter-mark-awarders to adopt to tackle casualisation (Megoran and Mason 2020). In that report, we recognise what Stoica and colleagues argue when they note that because 'many tenure-track scholars benefit from the precarity of others' precarity demands a shared sense of responsibility and a willingness to take action (2019: 81). The acknowledgement that solving precarity requires collective approaches of solidarity and the need to remember 'we are all members of the academic proletariat' is the conclusion of much work on casualisation (Hose and Ford 2014). It is our argument that understanding the ways in which casualisation is dehumanising can produce such collective acts of solidarity that remind us of our shared humanity. The battle against casualisation cannot merely be fought in terms of arguments about well-being, equality and fairness, important though those are. It cannot be waged by simply insisting that, by casualisation, we are 'legitimizing the devaluing of education through the devaluing of educators' (Clark 2019: 141), true though that is. Nor can it be won simply by an explication of the economic forces that produce precarity in capitalist markets or the public and education sectors that are forced to mimic them, indispensable though those arguments are. It is not just that casualisation is the product of a reprehensible political economy that harms both education and those who deliver it. Rather, we insist that it is an affront to the very meaning and nature of being human. It is, as a perspective built on African American theological anthropology insists, objectionable and obnoxious on the most fundamental level of our creatureliness because, rather than recognising workers' inherent dignity, it treats them as 'animated tools'. 
Managers of the neoliberal university might claim that their staff matter or that they are 'investors' in people, but these 'people' are sickly caricatures of real humans, the warped imaginations of 'Human Resources' departments - barely recognisable as the intrinsically and inherently valuable and precious beings created imago Dei. When push comes to shove, they justify the business model of casualisation by saying that bottom lines, student recruitment, research metrics and playing the game of audit regimes matter. Resistance to casualisation must begin simply by insisting upon something more fundamental: people matter.

\section{Acknowledgements}

We would like to acknowledge the support of the William Leech Research Fund for supporting this research, for Dan Hirslund for pointing us to relevant literature, to the University and College Union for working with us and supporting a policy report based on this research, and to the editors and three anonymous reviewers of this article. We are most indebted to everyone who kindly allowed us to interview them.

Olivia Mason conducts research that explores questions of cultural heritage, identity, territory and movement - specifically walking - in the Middle East. Since completing her PhD in the Geography Department at Durham University, she has been employed as a Fixed-Term Lecturer in Political Geography at Newcastle University, and is currently an ESRC Postdoctoral Fellow at Newcastle University.

Email: olivia.mason2@newcastle.ac.uk

Nick Megoran undertakes research about how human lives are valued or devalued. He explores this in a variety of contexts including UK secondary and higher education, geopolitical theory, theologies of peace and war, and nationalism and everyday life in the Danish-German and Uzbek-Kyrgyz borderlands. Email: nick.megoran@ncl.ac.uk 


\section{Olivia Mason and Nick Megoran}

\section{Notes}

1. 'So God created mankind in his own image, in the image of God he created them; male and female he created them' (Genesis 1: 27, Holy Bible, New International Version. London: Hodder and Stoughton, 1973, 1984).

2. The Magna Charta Universitatum (Great Charter of Universities) is a document published in 1988 by Bologna University and (as of March 2021) signed by over 900 universities worldwide, which states the importance of principles of academic freedom and institutional autonomy for universities. See http://www.magna-charta.org/magna-charta-universitatum.

\section{References}

Bain, P., J. Vaes and J.-P. Leyens (2014a), 'Advances in understanding humanness and dehumanization', in P. Bain, J. Vaes and J.-P. Leyens (eds), Humanness and Dehumanization (London: Routledge), 1-9.

Bain, P., J. Vaes and J.-P. Leyens (2014b), Humanness and Dehumanization (London: Routledge).

Baker-Fletcher, G. (1993), Somebodyness: Martin Luther King, Jr., and the Theory of Dignity (Minneapolis: Fortress Press).

Bosanquet, A., L. Mantai and V. Fredericks (2020), 'Deferred time in the neoliberal university: Experiences of doctoral candidates and early career academics', Teaching in Higher Education 25, no. 6: 736-749. https://doi.org/10.1080/13562517.2020 .1759528 .

Brown, K. (2004), 'Human resource management in the public sector', Public Management Review 6, no. 3: 303-309. https://doi.org/10.1080/1471903042000256501.

Bunderson, S. and J. Thompson (2009), 'The call of the wild: zookeepers, callings, and the double-edged sword of deeply meaningful work', Administrative Science Quarterly 54, no. 1: 32-57. https://doi.org/10.2189/asqu.2009.54.1.32.

Cant, C. (2019), Riding for Deliveroo: Resistance in the New Economy (Cambridge: Polity Press).

Caretta, M. A., D. Drozdzewski, J. C. Jokinen and E. Falconer (2018), “"Who can play this game?" The lived experiences of doctoral candidates and early career women in the neoliberal university', Journal of Geography in Higher Education 42, no. 2: 261-275. https://doi.org/10.1080/03098265.2018.1434762.

Clark, N. K. (2019), 'Shame and loathing in academia: For-profit education and the adjunct crisis', Transformations: The Journal of Inclusive Scholarship and Pedagogy 29, no. 2: 136-141.https://doi.org/10.5325/trajincschped.29.2.0136.

Cortez, M. (2010), Theological Anthropology: A Guide for the Perplexed (London: T\&T Clark). 
Cunningham, I., S. Baines and J. Shields (2017), “'You've just cursed us”: Precarity, austerity and worker's participation in the non-profit social services', Industrial Relations / Relations Industrielles 72, no. 2: 370-393. https://www.jstor.org/stable/26301316.

Gleerup, J., B. S. Nielsen, P. Olsén and N. Warring (2018), 'Prekarisering og akademisk arbejde' [Precarisation and academic work], Tidsskrift for Arbejdsliv 20, no. 1: 9-29. https://doi.org/10.7146/tfa.v20i1.108195.

Haire, M. (1970), 'A new look at human resources', Industrial Management Review 11, no. $2: 17-23$.

Harding, V. (2000), Martin Luther King: The Inconvenient Hero (New York: Orbis).

Hirslund, D., S. R. Davies and M. Monka (2018), Report on National Meeting for Temporarily Employed Researchers, Copenhagen September 2018 (Copenhagen: Dansk Magisterforening). https://dm.dk/media/12351/report_national_meeting.pdf.

Hose, L. and E. J. Ford (2014), 'Caught in the adjunct trap', Learning and Teaching 7, no. 1: 46-56. https://doi.org/10.3167/latiss.2014.070104.

Hyatt, S. B. (2004), 'Keeping the Bureaucratic Peace: "Audit Culture and the politics of accountability, new managerialism, and neoliberal governance”, American Anthropological Association invited roundtable session, Chicago, 21 November 2003', Anthropology Today 20, no. 3: 25-27. https://www.jstor.org/stable/3695127.

Jackson, T. (2007), From Civil Rights to Human Rights: Martin Luther King, Jr. and the Struggle for Economic Justice (Philadelphia: University of Pennsylvania Press).

Johnston, R. and J. Sidaway (2016), Geography and Geographers: Anglo-American Human Geography Since 1945 (6th ed.) (Abingdon: Routledge).

King, Martin Luther, Jr. (1965), 'Man in a revolutionary world', speech at the United Church of Christ, Chicago, 6 July. The University of Memphis Libraries, https:// www.memphis.edu/libraries/mlk50/speech.php.

King, Martin Luther, Jr. [1967] (1986), 'Where do we go from here?', in: J. Washington (ed.), A Testament of Hope (New York: HarperCollins), 555-633.

Leathwood, C., and B. Read (2020), 'Short-term, short-changed? A temporal perspective on the implications of academic casualisation for teaching in higher education', Teaching in Higher Education 1-16. https://doi.org/10.1080/13562517.2020.1742681.

Legge, K. (2005), Human Resource Management: Rhetorics and Realities (Basingstoke, UK: Palgrave Macmillan).

Leyens, J.-P. (2009), 'Retrospective and prospective thoughts about infrahumanization’, Group Processes \& Intergroup Relations 12, no. 6: 807-817. https://doi.org/ $10.1177 / 1368430209347330$.

Loveday, V. (2018), 'The neurotic academic: Anxiety, casualisation, and governance in the neoliberalising university', Journal of Cultural Economy 11, no. 2: 154-166. https:// doi.org/10.1080/17530350.2018.1426032. 
Marvit, M. (2014), 'How crowdworkers became the ghosts in the digital machine', The Nation, 5 February. https://www.thenation.com/article/archive/how-crowdworkers -became-ghosts-digital-machine/.

Mayo, E. (1949), The Social Problems of an Industrial Civilisation (London: Routledge and Kegan Paul).

Mazzetti, A. and J. Blenkinsopp (2012), 'Evaluating a visual timeline methodology for appraisal and coping research', Journal of Occupational and Organizational Psychology 85, no. 4: 649-665. https://doi.org/10.1111/j.2044-8325.2012.02060.x.

Megoran, N. and O. Mason (2020), Second Class Academic Citizens: The Dehumanising Effects of Casualisation in Higher Education (London: University and College Union).

McGuire, I. (2006), Incredible Bodies (London: Bloomsbury).

Mikkola, M. (2016), The Wrong of Injustice: Dehumanization and Its Role in Feminist Philosophy (Oxford: Oxford University Press).

Navarro, T. (2017), 'But some of us are broke: Race, gender, and the neoliberalization of the academy’, American Anthropologist 119, no. 3: 506-517. https://doi.org/10.1111/ aman.12888.

Noon, M., P. Blyton and K. Morrell (2013), The Realities of Work: Experiencing Work and Employment in Contemporary Society (London: Palgrave Macmillan).

O’Connor, E. (1999), 'Minding the workers: the meaning of "human" and "human relations” in Elton Mayo', Organization 6, no. 2: 223-246. https://doi.org/ $10.1177 / 135050849962004$.

Scholz, T. (2017), Uberworked and Underpaid: How Workers Are Disrupting the Digital Economy (Cambridge: Polity Press).

Sennett, R. (1988), The Corrosion of Character: The Personal Consequences of Work in the New Capitalism (London: W.W. Norton).

Slater, T. (2012), 'Impacted geographers: A response to Pain, Kesby and Askins', Area 44, no. 1: 117-119. https://doi.org/10.1111/j.1475-4762.2011.01067.x.

Standing, G. (2016), The Precariat: The New Dangerous Class (London: Bloomsbury).

Stoica, G., J. Eckert, K. Bodirsky and D. Hirslund (2019), 'Precarity without borders: Visions of hope, shared responsibilites and possible responses', Social Anthropology/ Anthropologie Sociale 27, S2: 78-96. https://doi.org/10.1111/1469-8676.12700.

Storey, J. (2007), Human Resource Management: A Critical Text (London: Cengage).

Strauss, K. (2017), 'Labour geography 1: Towards a geography of precarity?', Progress in Human Geography 42, no. 4: 622-630. https://doi.org/10.1177/0309132517717786.

Taskin, L. and J. Ndayambaje (2018), 'Revealing the dominant anthropological consideration of humankind in the teaching of Human Resource Management: A critique of individual performance evaluation', Ephemera 18, no. 2: 277-301. http://ephemerajournal.org/contribution/revealing-dominant-anthropological -consideration-humankind-teaching-human-resource. 
Taylor, Frederick (1911), The Principles of Scientific Management (Project Gutenberg EBook).

The Analogue University (2019), 'Correlation in the data university: Understanding and challenging targets-based performance-management in higher education', ACME: An International Journal for Critical Geographies 18, no. 6: 1184-1206. https:// acme-journal.org/index.php/acme/article/view/1725.

UCU (University and College Union) (2019), Counting the Costs of Casualisation (London: University and College Union). https://www.ucu.org.uk/media/10336/ Counting-the-costs-of-casualisation-in-higher-education-Jun-19/pdf/ucu_ casualisation_in_HE_survey_report_Jun19.pdf (accessed 27 February 2021).

UNESCO (1997), Recommendation concerning the Status of Higher-Education Teaching

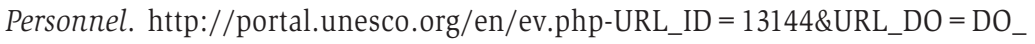
TOPIC\&URL_SECTION = 201.html (accessed 27 February 2021).

Wall, T. and S. Wood (2005), 'The romance of human resource management and business performance, and the case for big science', Human Relations 58, no. 4: 429-462. https://doi.org/10.1177/0018726705055032.

Weinert, M. (2015), Making Human: World Order and the Global Governance of Human Dignity (Ann Arbor: University of Michigan Press).

Wills, R. (2009), Martin Luther King, Jr., and the Image of God (Oxford: Oxford University Press). 